\title{
Moisture, Water Holding, Drying and Wetting in Forest Soils
}

\author{
Pavel Blažka1,2, Zofia Fischer ${ }^{3 *}$ \\ ${ }^{1}$ Faculty of Science, University of South Bohemia, České Budějovice, Czech \\ ${ }^{2}$ Present Address: Ulrychova 23, 16200 Praha 6, Czech \\ ${ }^{3}$ Department of Applied Ecology, John Paul II, Catholic University of Lublin, Lublin, Poland \\ Email: pavelblazka@seznam.cz, ${ }^{*}$ zofiaf@plusnet.pl
}

Received 18 March 2014; revised 18 April 2014; accepted 25 April 2014

Copyright (C) 2014 by authors and Scientific Research Publishing Inc.

This work is licensed under the Creative Commons Attribution International License (CC BY). http://creativecommons.org/licenses/by/4.0/

(c) (i) Open Access

\begin{abstract}
Relationship of soil and water is generally considered as important in soil science. To specify it further we studied two different soils in 2012-2013, three additional soils once and made several series of experiments with drying and wetting of the soils. Principal parameters studied were the gravimetric water content (GWC), water holding capacity (WHC), soil organic matter (SOM), their correlations and rates of change in drying or wetting. The three parameters are significantly intercorrelated. Distribution of GWC in the replicates of soils dried both in nature and in experiments was narrower than that in wet soils, while WHC changed less in drying. The correlations (GWCWHC) became steeper (the slope coefficient higher) and the coefficient of determination ( $\left.R^{2}\right)$ lower. Attempts to increase WHC in wet soils with a high WHC even further were not successful. Drying may be fast or slow; rates of increase of WHC in wetting were all low, both in field and in the

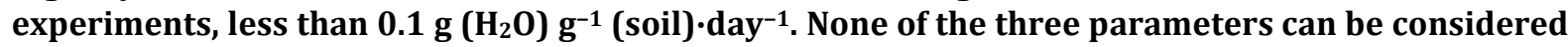
as fixed characteristics of forest soils.
\end{abstract}

\section{Keywords}

Soil-Water Relationships, Climate Change, Water Holding Capacity

\section{Introduction}

Relationship of soils and water is in a broad sense considered important in the soil literature for understanding of the structure and biology of soils and for interaction with the atmosphere and the climate. This aims towards two goals: a) To quantify the state of the soil; for this simple mass ratio water/soil, the gravimetric water content

\footnotetext{
*Corresponding author.
} 
(GWC) is a frequently used tool [1] [2], and no serious problems are encountered. b) To quantify the tendency of soils to attract or move water measurable as negative pressure, it was called water potential, developed early in $20^{\text {th }}$ century [3] [4]. Water holding capacity (WHC) is defined as the amount [g] of water per g dry soil retained against gravity when water is in excess. It is used quite often; it appeared in at least 64 abstracts of papers published during the last years by Elsevier and Springer publishing houses. It is frequently considered as fixed characteristics of soils [5] [6], a characteristics of soil moisture [7] and/or characteristics that correlate with biological activities [8] [9]. On the contrary it is mostly omitted by recent larger compendia [10] [11]. Romano and Santini [12] and many before refer to an analogical value - the field capacity. Illsted et al. [13] considered WHC as the best index of soil moisture. Evidently, there is no consensus on the definition and utility of WHC.

In times these goals were formulated (1905-1920), physicists and chemists understood attraction or repulsion between chemical and/or physical bodies incompletely; these phenomena were later referred as cohesive and/or adhesive intermolecular forces, or adsorption [14]. They were eventually understood [15] and are now called mostly "weak interactions". Other attempts to understand them physically in soils during the first half of $20^{\text {th }}$ century involved primarily combination of the capillarity derived water potential with other well defined potentials related to water or aqueous solutions. The water potential is now generally referred as sum of several (4 - 6) potentials, but Young and Sisson rightly consider "it is theoretically invalid for them to be treated as additive" [16]. Most of the researches were done in the field, it aimed towards evaluation of situation on particular spots, while properties or factors and relationships were rarely quantified or correlated quite sensibly.

To explore physical and/or biological relationships, more controlled laboratory experiments on simpler and more uniform setups, necessarily of smaller size than natural blocks of soil, are needed; soil preparations might be an adequate name or description. Both approaches are inevitable in soil research, have to understand and respect each other.

The aim of the current study is to explore the water holding capacity (WHC) which was introduced under a slightly different name also early in $20^{\text {th }}$ century [17] and is defined as "mass of water resisting drainage by gravity in a given mass of soil” [18]: is it a fixed characteristic of a particular soil, are there any relationships between WHC, GWC and SOM, what is the role of SOM and how are the relationships influenced by drying and wetting of soils. We approached these questions by studying in detail two very different forest soils during the 2012 growing season. In the second half of summer, we investigated three other soils once. Laboratory studies on the role and changes of GWC and WHC in drying and wetting of the two soils were aimed towards getting some insight on probable alterations of soils in the incoming weather changes.

\section{Material and Methods}

\subsection{The Sites}

The study is largely based on two different soils in the Kampinos forest (Geographic coordinates are: $52^{\circ} 20^{\prime} 212^{\prime \prime} \mathrm{N}, 020^{\circ} 51^{\prime} 260^{\prime \prime} \mathrm{E}$ ) on the northern outskirts of the city of Warsaw (Poland): The climate of the area is mild, in particular years changing between Atlantic and more continental, mean annual temperature is $8.9^{\circ} \mathrm{C}$, mean precipitation $554 \mathrm{~mm}$ for years 2000 till 2013 (Polish meteo service: www.weatheronline.pl). Both soils are on postglacial dunes, at present some dunes are up to $25 \mathrm{~m}$ high.

Site A is below the apparent dunes in a broad leaved section of the forest, crown coverage is $100 \%$, principal tree species are: alder-Alnus glutinosa (L.), oak-Quercus robur L., horn beam-Carpinus betulus L., pinePinus sylvestris L., birch—Betula pendula Roth., maple—Acer platanoides L. The soil is a histosol.

Soil B is a sandy podzol (spodosol) from a clearer place on top of a postglacial dune, the crown coverage is about $40 \%$, and principal trees are Betula pendula Roth. and Pinus sylvestris L.

In winter (Jan 4 _ thaw on April 14, 2013) our loggers (iButton Hygrochron Temperature loggers, Maxim Integrated, Rio Robles, CA, USA) registered changes at the rate of 6 points per day at the depth of $8 \mathrm{~cm}$ between 2_3.5 $5^{\circ} \mathrm{C}$ on the spot $\mathrm{A}$, and between $-1 \_0.5^{\circ} \mathrm{C}$ on the more exposed spot $\mathrm{B}$. In summer (June 1_Aug 15, 2013) the respective variations were $11.5 \_17.5^{\circ} \mathrm{C}$ in $\mathrm{A}$ and $15.5 \_24.5^{\circ}$ in $\mathrm{B}$ respectively. The two spots are approximately $110 \mathrm{~m}$ apart, elevation of site A is $81 \mathrm{~m}$ and of B $89 \mathrm{~m}$. In both soils particles with diameter $>0.1 \mathrm{~mm}$ represented $>50 \%$ (Żukowska, unpublished data).

In August we included one sampling of three other soils from the same area (within $500 \mathrm{~m}$ off point A) to determine, if they would exhibit similar characteristics: soil C is a thin layer of soil just below "pillows" of moss 
(presumably family Hylocomiacea) on a sandy substrate with a SOM of 4.6\%; soil D is below a stand of blueberry plants with a SOM of 13\%; E-soil had a SOM of $21.5 \%$, it was similar to soil A, but mostly wetter, currently appearing dry.

\subsection{Soil Sampling}

The soils were sampled for estimates of WHC, GWC and SOM, the soils were sampled four times during the vegetation season 2012 from areas of approx. $100 \mathrm{~m}^{2}$ each. A random block design was applied on two rectangles $5 \times 3.5 \mathrm{~m}$ each. In each of the two rectangles were 70 squares $0.5 \times 0.5 \mathrm{~m}$ each, arranged in ten rows and seven columns. The centers of these squares were sampling points by a hand corer (diameter $34 \mathrm{~mm}$ ). The situation in the field did not permit squares instead of rectangles. Random numbers determined the sequence and point of the sampling; this was identical in the two rectangles, one for soil A, the other for B.

There are a lot of random number sequences on the net, the addresses tend to change in time. We have created our sequence of 70 numbers in July 2012; they were derived from noise in the zener diode and seem to be very similar to the present address: www.motron.com/products info.php/products_id/137. The numbers were assigned to the points in columns starting from column1 till column 7 . The points were also similarly characterized by a natural series of numbers. Each column of ten random and natural numbers corresponds to one sampling starting July 2012 till Aug. 2013. The position of the random numbers determines sequence and place of the point in the sampling scheme, while the natural numbers are working numbers in the process.

After finishing the whole scheme we filled both GWC data into the rectangles, run a number of regressions across (columns, rows, diagonals) with all GWC data for soil A and B respectively and we found all regression coefficients are $r<0.224$. As GWC, WHC and SOM are significantly inter-correlated; this applies also for the latter two sets of data. This suggests that the sampling scheme was not corrupted by any outside gradient (e.g. east-west, north-south). At the rectangles we took samples in April 2012 and also for the drying and wetting experiments. Soils were randomly sampled from the A1 layer at depth of 5 to $15 \mathrm{~cm}$, were $5 \mathrm{~mm}$ sieved; larger objects were discarded. Ten independent multiples comprised each sampling. In treatment of soils we used recently collected (after less than $15 \mathrm{~h}$ ) fresh soils at their natural moisture content. For experiments we used freshly collected bulk samples (fre), or samples dried just below $30^{\circ} \mathrm{C}$ without direct access of sun light ( $30 \mathrm{dry}$ ).

\subsection{Laboratory Analyses}

\subsubsection{GWC and WHC Estimation}

Our procedure was based essentially on Grace et al, Priha and Smolander [19] [20] with following modifications: To saturate the soils with water we mixed the soil samples (usually $10 \mathrm{~g}$ of wet soil) with $50 \mathrm{ml}$ of ultrapure Q water (Millipore ${ }^{*^{\circledR}}$ ) in plastic vials. Our weighing accuracy was to $10 \mathrm{mg}$. After 30 minutes we transferred the slurry quantitatively on folded filter paper (Macherey-Nagel ${ }^{\circledR}$, white, MN $640 \mathrm{~m}$,) in a plastic funnel. The drop-off time varied among the soils and even within one soil type according to its condition: for $10 \mathrm{~g}$ samples of the two soils it ranged between 30 minutes to 8 hours. This suggests different sizes of soil aggregates, finer particles clogging the filter more quickly and thus prolonging the drop-off time; this may be in future a useful parameter for defining the state of soils. We recorded the weights of vials with dropped off water at $30 \mathrm{~min}$ intervals till the soil began to appear dry. When the weights did not increase, we took the weights of the wet mass of soil in the filters. We also spread the funnel side of the filters after lifting them from the funnels on kitchen paper tissue for a few seconds to remove water retained between the funnel and the filter paper. Weights of dry (fd) and wet filters (fw), fresh soil (sfre), water-flooded soil in filter (swf) and soil dried at $105^{\circ} \mathrm{C}$ with filter (sdf) were basis for calculation of both GWC and WHC.

$$
\begin{aligned}
& \mathrm{GWC}=[\text { sfre }-(\text { sdf }-\mathrm{fd})] /(\text { sdf }-\mathrm{fd}) \\
& \mathrm{WHC}=(\text { swf }-\mathrm{fw})-(\text { sdf }-\mathrm{fd}) /(\text { sdf }-\mathrm{fd})
\end{aligned}
$$

\subsubsection{Soil Organic Matter}

SOM was estimated as loss of weight in ignition (LOI) at $500^{\circ} \mathrm{C}$ on selected samples. This is enabled by absence of carbonate in our soils as shown by numerous measurements of $\mathrm{pH}$ done in the past and checked occasionally during the present work. GWC and WHC are expressed in the literature alternatively as ratios or percentages. 
The percentage is given as \%WHC or WHC\%, the former is generally the above ratio multiplied by 100 , and the latter is generally the percentage of the (maximum) water holding capacity estimate for a particular sample, but the expressions are not standardized. The reader is frequently forced to find the correct meaning according to the context of the experiment and therefore we chose to use the non-dimensional ratios for all three parameters in the present context.

\subsection{Experimental}

Experiments were designed to determine the rates of attaining new equilibriums between the soils and water after drying or wetting the soils, mostly on soil A. SOM was estimated in some selected experiments.

\subsubsection{Drying}

The slow drying experiment was performed in closed $100 \mathrm{ml}$ vials (PS\#0.65 mm), with $10 \mathrm{~g}$ of wet soil in each of 50 vials (mean GWC ranged from 1.28 to 1.19), no water was added. Ten replicates were analyzed each time for both GWC and WHC on Days 1, 8, 15 and 22. A similar experiment was run with soil B. Evaporation occurred, but was limited predominantly by the slow diffusion of gases including water vapor through the plastic of the vials.

The fast drying experiment was performed in open vials arranged similarly. We placed $10 \mathrm{~g}$ samples into each of 60 open vials and 10 replicates were taken for the analysis of GWC and WHC on Days 1, 3, 6, 9, 10 and 12. Relative air humidity was between $41 \%$ and $58 \%$, air temperature ranged within $16.4^{\circ} \mathrm{C}-18.2^{\circ} \mathrm{C}$. Starting GWC was 3.35.

The low-moisture (GWC at start 0.84 ) drying experiment was performed in vials covered with linen to slow the evaporation rate. Temperature was $18.2^{\circ} \mathrm{C}$, to $19.2^{\circ} \mathrm{C}$; relative air humidity ranged between $60 \%$ and $67 \%$. Samples (a total of 50 vials, $10 \mathrm{~g}$ of wet soil in each) were analyzed again per 10 replicates at on Days 0, 6, 10 and 14-at completion of the experiment. The remaining samples were used in the rewetting experiment.

\subsubsection{Wetting}

Short (up to $48 \mathrm{~h}$ ) wetting experiments on wet soils showed very slow if any changes in the WHC (data not shown). Therefore we performed longer experiments, all with soil A.

The first rewetting experiment involved soil after the low-moisture drying experiment 3. On Day 14 of the experiment the last ten samples were halved: The mean loss of dried soil during the division of samples was $0.01 \mathrm{~g}(0.16 \%)$, and the mean ratio of masses (undivided/sum of divided samples) was 1.002 . The divided samples were placed into $40 \mathrm{ml}$ glass vials with screwed air-tight covers. The experiment was continued until Day 32 after the start of the experiment (Day 17 of rewetting); dry soil mass was about $2.75 \mathrm{~g}$ instead of approximately $5.6 \mathrm{~g} / \mathrm{vial}$ in the first part of the experiment. Added water was $2.3 \mathrm{ml}$ of water per glass vial $(0.84$ $\mathrm{ml} \cdot \mathrm{g}^{-1}$ ); GWC increased from 0.074 at the start of drying to 0.92 after wetting and remained so to the end of the experiment. The glass vials were sampled on Days 10 and 17 after initiation of rewetting.

In the second rewetting experiment we estimated GWC and WHC of the fresh soil, the rest of the bulk sample was 30 dried, the dried soil was divided into fifty $40 \mathrm{ml}$ glass vials with air-tight covers (per approx. $8.8 \mathrm{~g}$ dry soil) and $10 \mathrm{ml}$ water $(1.14 \mathrm{ml}$ water/g dry soil) per vial. On the Days $0,3,6,13,23$ and 28 the contents of the vials were analyzed for GWC and WHC, with ten replicates each time.

This experiment was conducted to show a further increase in the WHC in a wet soil. Forty nine glass vials with air tight covers contained approximately $10 \mathrm{~g}$ of soil each, seven were analyzed at the initiation of the experiment and the rest was divided into three rewetting groups: a) with $2.5 \mathrm{ml}$ water, b) $5 \mathrm{ml}$ water, c) $7 \mathrm{ml}$ water added per vial. Seven vials of each variant were analyzed on Days 14 and 39.

\subsection{Statistical Analysis}

The statistical calculations were standard, and included primarily means, standard deviations (s), coefficients of variation (cv), standard errors (se), two-sided t-tests to determine the significance between means of samples in drying or wetting, correlations and regressions (slope coefficient- $\beta_{1}$ indicating rate, if time is the independent variable), and their confidence intervals. The calculations were performed in Microsoft-Excel 2010. We plotted all relationships, none of the WHC-GWC relationships showed any sign of significant non-linearity. The variability in the dry soil B approached our error values, so we studied some slow changes in the more variable soil A. 
The coefficient of determination $\left(\mathrm{R}^{2}\right)$ is the ratio of the sum of squares due to the regression to the total sum of squares [21]. Drying decreases the range and thus the sum of squares of both GWC and WHC and of the total sum of squares. This then results in a decrease of the coefficient of determination.

An increase of the rate in the regression after drying results from a narrower range of GWC due to drying and a less changed WHC; ratio of the WHC change per unit change of the GWC is the slope coefficient. This supports the requirement to state the range of a particular relationship (regression) for which it was calculated.

\section{Results}

\subsection{Growing Season 2012}

Data on freshly collected soils in summer 2012 are summarized in Figure 1. We found a correlation between the WHC and GWC for soil A that was maintained from early April until September 2012, while the mean GWC decreased from 2.70 to 0.55 (Figure 1). Time is thus a second regressor in the background of the correlation; it will be applied later as estimate of rates. Not only means, but all data on soils B through E, are very comfortably included within the confidential limits of the regression at $P<0.01$ ). All standard error whiskers are within the point icons (se $\leq 0.33 \mathrm{WHC}$ ). Soil A showed a high variability throughout the growing season of 2012 . Although the same number of data points were obtained for soil B as for soil A, soil B had a rather limited variability of GWC (range 0.03 till 0.14) and therefore a different WHC-GWC correlation [WHC $=2.11$ (se = $\left.0.0061) \times G W C+0.30 ; R^{2}=0.62, N=40\right]$. On the scale of the Figure 1 data for $B$ are presented as a point estimate (mean). A formalization of the joint WHC-GWC relationship for both soils was not done; because the large amount of data at the lower end of the relationship would result in a grossly non-normal distribution. There is no overlap between the A and B WHC and GWC data. This so far refers to the relationship on the broad scale. Within individual samplings (per 10 replicates) the relationship was more variable, but nevertheless in freshly collected soils WHC was always >GWC, even immediately after heavy rains and in soil E sampled in the dry period next to a muddy pool. Nearly all of these partial correlations were highly significant.

Similar correlations were found between SOM and WHC (Figure 2) and also for SOM-GWC for soils A and B: GWC $=3.425 \times$ LOI $+0.0509, \mathrm{R}^{2}=0.7824, \mathrm{~N}=115$. Though samples for SOM estimates were not collected strictly systematically, the relationships nevertheless comprise data for the whole season, fresh and dried samples in nature and in experiments. The three parameters are thus interconnected to a "correlation triangle". It suggests that the three parameters likely participate in a process or phenomenon.

The GWC of soils A and B kept decreasing from April to September indicating continuous drying of the soils in their natural environment as suggested by slope coefficient of regression of mean GWC to day of the year (doy). It was approximately $0.45 \mathrm{GWC} \cdot \mathrm{month}^{-1}$ for the means of soil $\mathrm{A}, \mathrm{R}^{2}=0.92$. Data for soil $\mathrm{B}$ (not shown) indicate fluctuations within the narrow limits rather than a clear trend. Evidently, GWC and WHC of soils A and B did change throughout the season and were not fixed properties of any soil. The mean GWCs and WHCs for

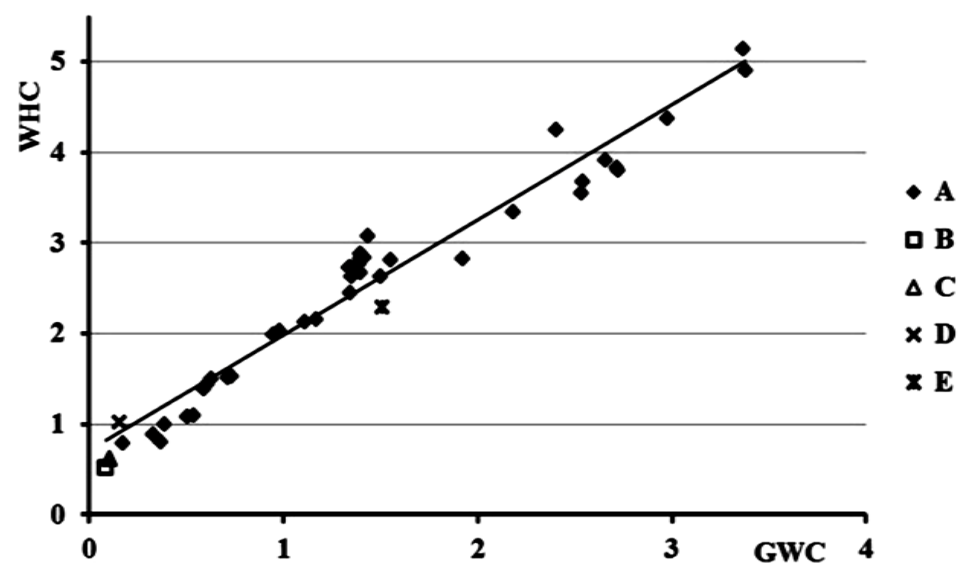

Figure 1. Correlation WHC-GWC for soil A in growing season $2012, \mathrm{R}^{2}=$ $0.95, \mathrm{WHC}=1.27(\mathrm{se}=0.013) \times \mathrm{GWC}+0.72(0.095), \mathrm{N}=40$; soil $\mathrm{B}: \mathrm{N}=40$; soils C - E: $\mathrm{N}=10$ each; soils B - E: means. 


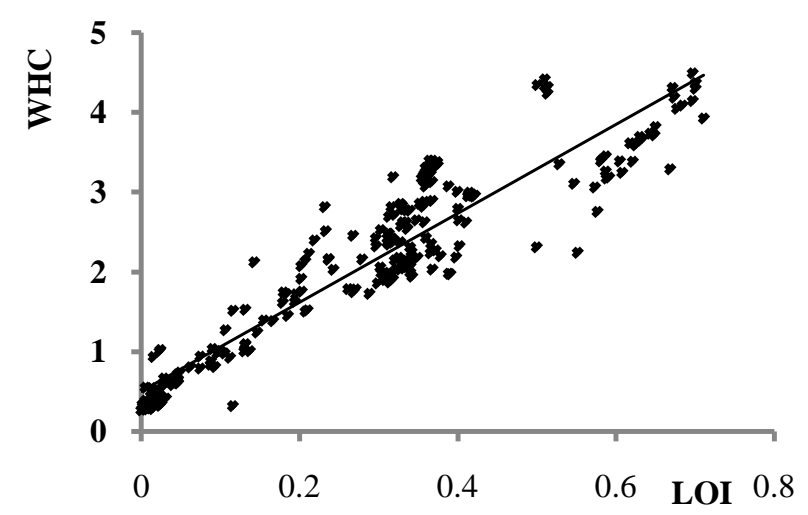

Figure 2. Correlation SOM-WHC. Soils A through E, A and B fresh, 30dried and water sieved. Years 2012 and 2013, N = $240, \mathrm{WHC}=5.58 \times \mathrm{LOI}+0.50, \mathrm{R}^{2}=0.88$.

soil $B$ and soils $C$ through $E$ followed the regression line for soil A; there were no experimentally dried soils in this dataset. In fall 2012 on the site B some of the birches died and decayed, the place was visited by a herd of wild pigs and GWC went up to 0.384 and WHC to 0.698. In June 2013 the three parameters dropped back to previous levels.

\subsection{Drying Experiments}

A comparison of fresh wet soils and the same soils dried at $30^{\circ} \mathrm{C}$ is shown in Table 1 . This indicates rather some trends, than true relationships, the respective cvs' of the ratios were mostly around one. Both GWC and WHC decreased after drying of the soils. In most cases, the percentage decrease of the mean GWC was much larger than that of the mean WHC. Additionally, the range of the GWC data decreased, while the changes in WHC were much smaller. This resulted in steeper slope coefficients in the regressions for the dried soils. In addition, the coefficients of determination $\left(\mathrm{R}^{2}\right)$ decreased as a result of drying. In the highly dried soils, the correlation between WHC and GWC ceased to exist; the coefficients of determination were close to zero. In Figure 3 we compare three drying experiments with soil A. The drying rates for the three experiments differ. Drying rate of soil $A$ in the forest $\left(0.015 \mathrm{~g} \cdot \mathrm{g}^{-1} \cdot \mathrm{day}^{-1}\right)$ is within the range of the experimental rates. The drying rates are shown by the slope coefficient $\left(\beta_{1}\right)$ in the regressions of mean WHC to time (days), we compare also the respective regression coefficients (r) and range of standard errors of the means (points). For the fast experiment the rate is an overall mean of 12 days, for a half of the period the changes were however non-significant (Days 3 to 6 , and 9 to 12), drying occurred actually in two ,jumps” at rates between 0.3 and 0.4 day $^{-1}$, though GWC was decreasing continuously. The overall linear rates were the same for WHC and GWC. In the slow-drying experiment, the decrease of WHC was continuous and approached the rate of soil change in the forest. A similar experiment with soil B showed a similar rate. WHC dropped from 0.439 to 0.340 in seven days and remained at that level till Day 21, se of the means varied between 0.0032 and 0.068 . Changes in the field took 135 days and involved large blocks of soils, largely vegetated by plants. The laboratory experiments took less than 25 days and were performed on small isolated items of soil. The low-moisture experiment did not reach the significance level $\mathrm{P}<$ 0.05 in 14 days.

\subsection{Wetting Experiments}

Three (re)wetting experiments are presented in Figure 4. The short lower broken line (low moisture wetting lmrw) is in fact a continuation of the drying experiment at low humidity after addition of water equivalent to water lost in drying $\left(0.84 \mathrm{~g} \cdot \mathrm{g}^{-1}\right.$ dry soil). WHC however increased slowly, non-significantly and did not approach the pre-drying level within 18 days; se of the means (points) were within 0.015 to 0.021 . Empty triangles (no line) show GWC level at the end of the drying and during the rewetting.

The fast rewetting line (frw) resulted from soil 30dried to GWC $=0.14$, more water $\left(1.14 \mathrm{~g} \cdot \mathrm{g}^{-1}\right)$ was added than in the previous experiment; the increase was significant at $\mathrm{P}<0.001$ after 12 days, se of the means (points) was between $0.015-0.060$. The WHC attained its original value on Day 29. Rate in the frw experiment was 


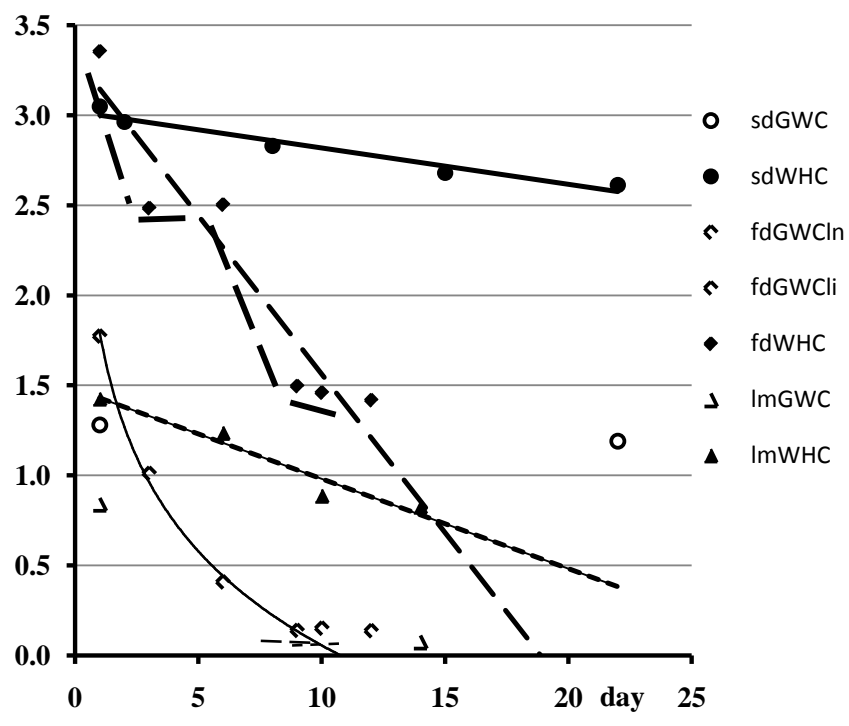

Figure 3. Course of WHC in slow drying (sd), low moisture drying (lm) and fast drying (fd) of soil A. Data plotted are means of ten data points each, $\beta_{1} \mathrm{~s}$ ' are rates of WHC change (= slope coefficients of regressions WHC to time [day]). Course of GWC is plotted for fast drying in two sections: in the first the decrease followed a logarithmic line (Day 1 to 9), no significant difference between Days 9 to 12. For $\mathrm{Im}$ and sd only the first and last points are shown, both courses were linear. For sdWHC: $\beta_{1}=0.021 \mathrm{day}^{-1}$, se $=0.018$ through $0.057, \mathrm{r}=0.98$; ImWHC: $\beta_{1}=0.05$ day $^{-1}$, se $=0.0067$ through $0.025, \mathrm{r}=0.97$; fdWHC: $\beta_{1}=0.176$ day $^{-1}$, se $=0.018$ through $0.057, \mathrm{r}=0.95 ; P<0.001$ for t-tests of the differences between the means of the data on Days 1 and 3, 6 and 9 respectively; there are however no significant differences between Days 3 and 6 and 9 to 12 .

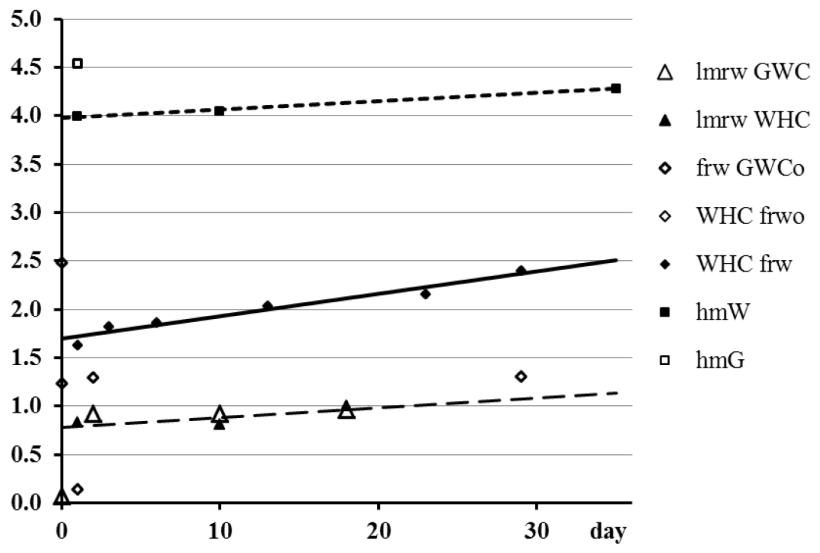

Figure 4. Course of WHC in low moisture rewetting (lmrw), fast rewetting (frw) and high moisture wetting $(\mathrm{hm})$ experiments on soil A. See text to Figure 3. GWC for lmrw just before the experiment is shown at Day 0 and during the experiment, for frw for fresh soil (Day 0, 30 dried soil at Day 1 and during the experiment (Days 2 and 29-no change). In hm it was at level shown for day 1.For WHCfrw: $\beta_{1}=0,023$ day $^{-1}, \mathrm{r}=0.97$, WHClmrw: $\beta_{1}=0.010$ day $^{-1}, \mathrm{r}=0.80$, WHChm: $\beta_{1}=$ 0.0087 day $^{-1}, \mathrm{r}=0.996$.

more than twice as fast as that in the slow condition. Higher moisture content (GWC at the start of rewetting) and/or the difference in water added per g dry soil probably contributed to the higher rate associated with the middle line. Empty diamonds show GWC of the fresh soil before 30 drying (Day 0), after 30 drying (Day 1) and during rewetting (Days 2 and 29). 
Table 1. Means and changes of GWC, WHC, the slope coefficients $\left(\beta_{1}\right)$ of their regressions in drying of soils at $<30^{\circ} \mathrm{C}$ in shade and the respective probabilities, $\mathrm{N}=10$ each. Soils defined by date as yymmdd. All drops in GWC are significant at $\mathrm{P}$ $<0.001$.

\begin{tabular}{|c|c|c|c|c|c|c|}
\hline soil & GWCavg & WHCavg & dGWC/dWHC & $\beta_{1}$ & $\mathrm{R}^{2}$ & dWHC: P < \\
\hline A120417_fre & 2.70 & 3.94 & & 1.50 & 0.97 & \\
\hline 30 dried & 0.14 & 2.72 & 2.82 & 3.33 & 0.83 & 0.05 \\
\hline A130419fre & 1.77 & 3.35 & & 1.32 & 0.74 & \\
\hline 30 dried & 0.77 & 2.17 & 0.85 & 1.04 & 0.43 & 0.001 \\
\hline A120804_fre & 1.38 & 2.76 & & 1.79 & 0.39 & \\
\hline 30dried & 1.01 & 2.48 & 1.31 & 13.59 & 0.71 & 0.001 \\
\hline sAfre.130703 & 1.24 & 2.48 & & 1.67 & 0.91 & \\
\hline 30 dried & 0.14 & 1.63 & 1.29 & 1.32 & 0.02 & 0.001 \\
\hline A120707fre & 1.17 & 2.21 & & 1.49 & 0.87 & \\
\hline 30dried & 0.17 & 1.96 & 3.95 & 3.68 & 0.45 & 0.001 \\
\hline B121013fre & 0.04 & 0.35 & & 1.16 & 0.5 & \\
\hline 30dried & 0.02 & 0.33 & 1.37 & 0.34 & 0.01 & 0.05 \\
\hline B120418fre & 0.10 & 0.49 & & 1.06 & 1.07 & \\
\hline 30 dried & 0.02 & 0.48 & 9.69 & 2.42 & 0.05 & $>0.05$ \\
\hline
\end{tabular}

The uppermost line shows an attempt to even further increase WHC in wet soils. The two lower wetting rates in the experiment 3 were not plotted in the figure; they indicated non-significant increase at $\leq 1.7 \mathrm{ml}$ water added to $1 \mathrm{~g}$ dry soil, $(P>0.05)$. The plotted line is for the addition of $2.3 \mathrm{ml}$ water $/ \mathrm{g}$ dry soil, it is significant in its second section only and the overall increase is only $7 \%$ of the original WHC. Moreover the validity of the t-test suggesting a significant difference in this line is undermined by the difference in variances at the two points on the line. In this experiment was GWC $>$ WHC: 4.54_4.28 at $\mathrm{P}<0.05$. This suggests that a further substantial increase of WHC after wetting very wet soils is unlikely, WHC $\approx 4.3$ appears to be approximate ultimate maximum for soil A. We were unable to increase WHC of a wet soil B in a similar experiment beyond 0.42 . This is evidently equivalent to situations generally described as saturated soil with zero potential.

The drying and watering experiments showed that drying may be slow or fast, not necessarily linear or continuous and may be slowed down by physical constraints. The WHC in most-experiments (with exception of wetting very wet soils) remained above the GWC. The process of increasing WHC by wetting is always a slow

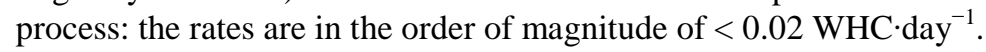

\section{Discussion}

Our field results (Figure 1 and Figure 2) indicated conclusively correlations of GWC WHC and SOM in five forest soils forming a "triangle" and suggesting involvement of the three parameters in the soil-water relationship. Changes of GWC were fast, medium or slow, while changes of WHC were much slower. An evident next step is to explore a more physical interpretation of these phenomena. Both GWC and WHC are the same ratio of mass of water to dry soil, just under different situations. While GWC is the ratio at the moment and circumstances given, water is present but not necessarily joined to soil aggregates, WHC is an estimate of how much water can be accommodated within the soil as defined by the present GWC and that's soils history, provided there is an excess of water. This leads to the consideration of structural qualities of the part of the soil matrix that is most likely responsible for the physical attraction of soil and water. Moisture content (GWC), WHC and SOM are generally higher in forest soils [22] than in agricultural soils. The correlations are not just a statistical relationship, but there is a strong physical connection in drying and wetting of the soils both in experiments and in the annual cycle. 
The role of "weak interactions" in SOM was proposed by Wershaw [23], later by [24] [25]. For soil moisture the most important "weak interactions" are the H-bridges (=H-bonds) connecting at a given moment polar functional groups on $\mathrm{C}$ atoms $\left(\mathrm{C}_{\mathrm{pol}}\right)$ of humic compounds with small molecular metabolites, with a number of water molecules and also water molecules one to another. This suggests an analogy to the solvation layer of native proteins.

We now accept a higher 3-D flexibility of organic compounds including humic. Not all covalent bonds are necessarily stiff, some may move (e.g. change the bond angle) to some extent if some energy (e.g. by heating or vibration) or a substitute group is introduced into the molecule, macromolecule or soil aggregate [26]. Energy of rotation along a simple C-C bond and energy of an H-bond are of the same order of magnitude [27], approx. 20 $\mathrm{kJ} \cdot \mathrm{mol}^{-1}$.

Approximately $50 \%$ of $\mathrm{C}_{\text {pol }}$ in carbon of humic materials were found by Schaumann, and Bertmer [25], they also report slow reforming of lost, abolished H-bridges, corresponding to slow rewetting in our experiments (Figure 4). Assuming hypothetically SOM $=0.35$ in soil A, 60\% C in SOM and WHC $=4.0$ results in requirement of at least $9 \mathrm{mmol} \mathrm{H}_{2} \mathrm{O}$ per mmol $\mathrm{C}_{\text {pol }}$. The energy of multiple $\mathrm{H}$-bridges on watered humic molecules might be perhaps able to reform the SOM molecules and also deal with the associated increase of entropy.

The organic constituents are also thought to be similarly interconnected with the mineral constituents of soils including coverage of inorganic particles by humic compounds [25] [28]-[30]. Water within soil aggregates interconnecting the aggregate constituents is now called "water bridges" [31]. For connections of SOM with quartz and alumo-silicates data in comparable units are badly needed.

Based on this line of thinking, the relationship between GWC, WHC, SOM and incorporation of water by H-bonds into molecules of humic compounds may be hypothetically seen as adjustment of their form in the soil by water molecules of moisture (GWC). The reformed soil would be thus enabled to accept additional water molecules, when more water becomes available after the next rainy period or ground water delivery. Our field observations and (re)wetting experiments suggested slow rates of these reformations, for a substantial increase of WHC in the field from e.g. 1.5 to 4.0 several months are required, one short and vigorous precipitation event would not change the WHC too much.

Timing of drying-rewetting cycles or dry-flood events rather than their intensity in the ongoing climate changes will be critical for the appraisal of their impact on soils. The slow restoration of WHC in dried soils, we have found, and the accelerating changes in the environment seem not to support maintenance of water in soils.

Relationship of GWC and WHC is by no means unidirectional, it is a true correlation both physically and statistically; we may expect soil with a higher WHC would likely keep water on the spot and maintain a higher GWC there. This may create an accelerating effect in progress of watering of soils.

\section{Conclusions}

1) WHC is not specific characteristics of forest soils, but rather of their actual state.

2) GWC, WHC and SOM are correlated under natural conditions in forest soils examined.

3) All three change during the year.

4) Drying of soils may be slow or fast, not necessarily continuous and linear.

5) Wetting of dried soils is always a slow process, WHC lags after GWC.

\section{References}

[1] Gardner, W.H. (1986) Water Content. In: Methods of Soil Analysis, Part 1. Physical and Mineralogical MethodsAgronomy Monograph No 9 (2nd Edition) (c) American Society of Agronomy, Soil Science Society of America, Madison.

[2] Reynolds, W.D. and Topp, G.C. (2008) Soil Water. Analyses, Principles and Parameters. In: Carter, M.R. and Gregorich, E.G., Eds., Soil Sampling and Methods of Analysis, CRC Press, Taylor \& Francis Group, Boca Raton.

[3] Buckingham, E. (1907) Studies on the Movement of Soil Moisture. US Department of Agriculture, Bureau of Soils No. 38.

[4] Gardner, W. (1919) The Movement of Moisture in Soil by Capillarity. Soil Science, 7, 313-317. http://dx.doi.org/10.1097/00010694-191904000-00008

[5] Mahe, G., Paturel, J-E., Servat, E., Conway, D. and Dezetter, A. (2005) The Impact of Land Use Change on Soil Water Holding Capacity and River Flow Modeling in the Nakambe River, Burkina-Faso. Journal of Hydrology, 300, 33-43. 
http://dx.doi.org/10.1016/j.jhydrol.2004.04.028

[6] Hedley, C.B. and Yule, I.J. (2009) Soil Water Status Mapping and Two Variable-Rate Irrigation Scenarios. Precision Agriculture, 10, 342-355. http://dx.doi.org/10.1007/s11119-009-9119-z

[7] Vengadaramana, A., and Jashothan, P.T.J. ( 2012) Effect of Organic Fertilizers on the Water Holding Capacity of Soil in Different Terrains of Jaffna Peninsula in Sri Lanka. Journal of Natural Product \& Plant Resources, 2, 500-503.

[8] Joergensen, R.G. and Potthoff, M. (2005) Microbial Reaction in Activity, Biomass, and Community Structure after Long-Term Continuous Mixing of a Grassland Soil. Soil Biology \& Biochemistry, 37, 1249-1258. http://dx.doi.org/10.1016/j.soilbio.2004.11.021

[9] Lawes, R.A., Olive, Y.M. and Robertson, M.J. (2009) Integrating the Effects of Climate and Plant Available Soil Water Holding Capacity on Wheat Yield. Field Crops Research, 11, 297-305. http://dx.doi.org/10.1016/j.fcr.2009.06.008

[10] Dane, J.H. and Topp, G.C. (2002) Methods of Soil Analysis. Part 4: Physical Methods. Soil Science Society of America, Inc., Madison, USA.

[11] Reynolds, W.D. and Topp, G.C. (2008) Soil Water. Analyses, Principles and Parameters. In: Carter, M.R. and Gregorich, E.G., Eds., Soil Sampling and Methods of Analysis (2nd Edition), Canadian Society of Soil Science. CDC Press, Taylor \& Francis Group, Boca 206 Raton.

[12] Romano, N. and Santini, A. ( 2002). Water Retention and Storage. Field. In: Dane, J.H. and Topp, G.C., Eds., Methods of Soil Analysis, Soil Science Society of America, Madison.

[13] Ilstedt, U., Nordgren, A. and Malmer, A. (2000) Optimum Soil Water for Soil Respiration before and after Amendment with Glucose in Humid Tropical Acrisols and a Boreal Mor Layer. Soil Biology \& Biochemistry, 32, 1591-1599. http://dx.doi.org/10.1016/S0038-0717(00)00073-0

[14] Stumm, W. and Morgan, J.J. (1996) Aquatic Chemistry. 3rd Edition, Wiley.

[15] Desiraju, G.R. and Steiner, T. (1999) The Weak Hydrogen Bond. In: Structural Chemistry and Biology, Oxford University Press, Oxford.

[16] Young, M.H. and Sisson, J.B. (2002) Tensiometry. In: Dane, J.H. and Topp, G.C., Eds., Methods of Soil Analysis Part. 4. Physical Methods. Soil Science Society of America Inc., Madison.

[17] Gardner, W. (1919) Capillary Moisture-Holding Capacity. Soil Science, 7, 319-324. http://dx.doi.org/10.1097/00010694-191904000-00009

[18] Gulledge, J. and Schimel, J.P. (1998) Moisture Control over Atmospheric CH4 Consumption and CO2 Production in Diverse Alaskan Soils. Soil Biology \& Biochemistry, 30, 1127-1132. http://dx.doi.org/10.1016/S0038-0717(97)00209-5

[19] Grace, C., Hart, M. and Brookes P.C. (2006) Laboratory Manual of the Soil Microbial Biomass Group. Rothamsted Research.

[20] Priha, O. and Smolander, A. (2003) Short-Term Uptake of 15NH4 into Soil Microbes and Seedlings of Pine, Spruce and Birch in Potted Soils. Soil Biology and Fertility of Soils, 37, 324-327.

http://dx.doi.org/10.1007/s00374-003-0601-x

[21] Ryan, T.P. (2009) Modern Regression Methods. 2nd Edition, Wiley Publishing, New Jersey.

[22] Tisdall, J.M. and Oades, J.M. (1982) Organic Matter and Water-Stable Aggregates in Soils. Journal of Soil Science, 33, 141-163. http://dx.doi.org/10.1111/j.1365-2389.1982.tb01755.x

[23] Wershaw, R.L. (1999) Molecular Aggregation of Humic Substances. Soil Science, 164, 803-813. http://dx.doi.org/10.1097/00010694-199911000-00004

[24] Piccolo, A. (2001) Thesupramolecular Structure of Humic Substances. Soil Science, 166, 810-832. http://dx.doi.org/10.1097/00010694-200111000-00007

[25] Schaumann, G.E. and Bertmer, M. (2008) Do Water Molecules Bridge Soil Organic Matter Molecule Segments? European Journal of Soil Science, 59, 423-429. http://dx.doi.org/10.1111/j.1365-2389.2007.00959.x

[26] McMurry, J. (2004) Organic Chemistry. 6th Edition, Brooks/Cole, Thomson Learning Company.

[27] Kodíček M., Karpenko V.( 2000) Biophysical Chemistry. 2nd Revised Edition, Academia, Prague (In Czech).

[28] Schaumann, G.E., Hobley, E., Hurrass, J. and Rotard, W. (2005) H-NMR Relaxometry to Monitor Wetting and Swelling Kinetics in High Organic Matter Soils. Plant Soil, 275, 1-20. http://dx.doi.org/10.1111/j.1365-2389.2007.00959.x

[29] Aquino, A.J.A., Tunega, D., Pašalić H., Schaumann, G.E., Haberhauer, G., Gerzabek, M.H. and Lischka, H. (2011) Study of Solvent Effect on the Stability of Water Bridge-Linked Carboxyl Groups in Humic Acid Model. Geoderma, 169, 20-26. http://dx.doi.org/10.1016/j.geoderma.2010.12.006

[30] Jäger, A., Schaumann, G.E. and Bertmer, M. (2011) Optimized NMR Spectroscopic Strategy to Characterize Water Dynamics in Soil Samples. Organic Geochemistry, 42, 917-925. http://dx.doi.org/10.1016/j.orggeochem.2011.03.021 
[31] Schaumann, G.E., Dörte Diehl, D., Bertmer, M., Jaeger, A., Conte, P., Alonzo, G. and Bachmann, J. (2013) Combined Proton NMR Wideline and NMR Relaxometry to Study SOM-Water Interactions of Cation-Treated Soils. Journal of Hydrology and Hydromechanics, 61, 50-63. http://dx.doi.org/10.2478/johh-2013-0007 